\title{
Dr. Horse
}

\section{Erhard Taverna}

Dr. med., Mitglied der Redaktion

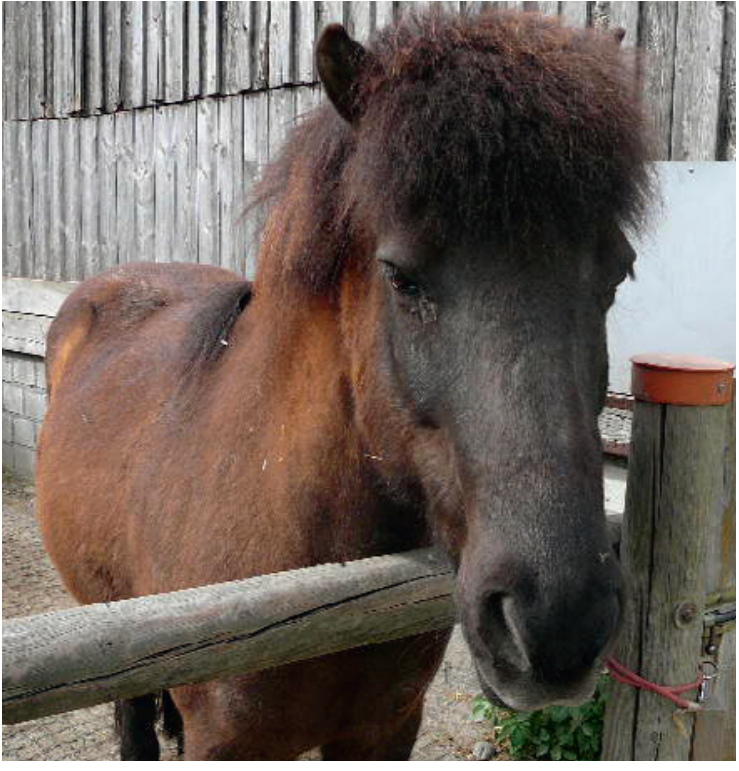

Die junge Frau wirkt kompetent. Sie steht ruhig da, beobachtet und filmt ab und zu das Geschehen. Am Ende wird ein Gespräch die Stunde beenden. Spatzen tschilpen, von der nahen Autobahn rauscht es unaufhörlich, ein typischer Stadtrand mit einer Reihe hässlicher Wohnblocks. Der Verkehrslärm scheint die Island-Ponies auf dem Hof nicht zu stören. Ein Wallach knabbert am spärlichen Gras entlang des umzäunten Pferchs. Bald soll er sich als Co-Therapeut auf einen Menschen einlassen. Eine erste Annäherung geschieht vorsichtig, der Hengst schleckt kurz die Hände und lässt sich tätscheln. Weisse Haarsträhnen in der Mähne schaffen eine emotionale Brücke. Die Interaktion geschieht averbal mit sanftem Druck, respektvoll beim Anblick der überlegenen, geballten Kraft. Immerhin erfolgt kein abwehrender Huftritt und das Flucht- und Herdentier lässt weitere Versuche zu.

Das pferdegestützte Coaching ist seit vielen Jahren zu einer anerkannten Methode der Rehabilitation, Psychotherapie und Schulung von Betriebsmitarbeitern geworden. Die domestizierten Tiere reagieren sensibel auf die Köpersprache des Menschen. Sie sind von Natur aus exakte Beobachter und reagieren auf launenhaftes Verhalten, Angst, Unsicherheit und Verspannungen. In dieser ersten Stunde geht es nur um Kontakt, Einfühlungsvermögen und Geduld. Der Hengst soll sich von seiner Gräsersuche abhalten und in eine bestimmte Richtung lenken lassen. Kein Rangduell und keine Dressur sind gefragt, nur konsequentes Verhalten und klare Zielvorstellungen. Ein zaghafter Klaps auf die Kruppe wird ignoriert, es darf schon etwas energischer sein. Der graue Gymnastikball wird beschnuppert, erregt aber nur für kurze Zeit die erwünschte Aufmerksamkeit. Erfolgreicher ist ein vorgehaltener strohgeflochtener Reifen, verbunden mit sanftem Drücken und Schieben. Schon ein halbwegs gelungener Parcours wird da für den Neuling zum Erfolgserlebnis. Pferde können nicht sprechen und nicht lügen, sie spüren was Sache ist, sie sind das Medium, das zu weiteren Reflexionen anregt. Es braucht also drei: die beobachtende Frau ausserhalb des Pferchs, den Mann, der sich auf das Tier konzentriert und ein Pony, das sein Verhalten widerspiegelt. Professionelles Coaching setzt eine seriöse Ausbildung voraus, wenn es darum geht, das Verhalten von Tier und Mensch zu interpretieren. Mit einer einzigen Stunde ist da noch wenig erreicht, es soll ja auch mehr sein als ein gemütlicher Tag auf einem Reithof. Die Anbieter sind zahlreich, die Versprechen oft etwas vollmundig. Der Tierkontakt soll in jeder Konfliktsituation Blockaden lösen, Stress abbauen und die Teamfähigkeit fördern. Pferdegestützte Persönlichkeits- und Führungsschulung an Seminaren ist beliebt. Es gibt Workshops, die sich explizit an Ärzte richten. Das systemische Coaching soll deren Achtsamkeit und Kommunikation verbessern. Wichtig ist in jedem Fall, dass das Erlebnis mit dem Pferd, eingebettet in einem soliden Theorieverständnis, analysiert wird. Die Interaktion macht nur Sinn, wenn sich die Methode didaktisch und methodisch begründen lässt. Wer nicht mit Pferden zu tun hat, muss sich erst darauf einlassen, muss offen, konzentriert und behutsam seine Scheu überwinden. Eine gute Erfahrung, die schon nach einer ersten Stunde ein Gefühl von Zufriedenheit und Vertrauen hinterlässt. Ein Weichmacher, ein Moment wortlosen Glücks. Kein Pferdeflüsterer war am Werk, doch das kleinste Erfolgserlebnis wirkt noch nach.

Es gibt auch Coaching-Angebote mit Lamas, Hunden, Wölfen und Greifvögeln. Doch die längste Zeit waren Pferde die engsten tierischen Partner des Menschen. Wie es dem Hengst während dieser Begegnung ging bleibt sein Geheimnis.

«Überlasst das Denken euren Pferden, sie haben die grösseren Köpfe» soll Friedrich der Grosse seinen Offizieren gesagt haben. Recht hatte er.

Bildnachweis

Erhard Taverna 